Research Article

\title{
Fungal Infections among Psoriatic Patients: Etiologic Agents, Comorbidities, and Vulnerable Population
}

\author{
Mostafa Chadeganipour, ${ }^{1}$ Shahla Shadzi, ${ }^{1}$ and Rasoul Mohammadi $\mathbb{D}^{1,2}$ \\ ${ }^{1}$ Department of Medical Parasitology and Mycology, School of Medicine, Isfahan University of Medical Sciences, Isfahan, Iran \\ ${ }^{2}$ Infectious Diseases and Tropical Medicine Research Center, Isfahan University of Medical Sciences, Isfahan, Iran \\ Correspondence should be addressed to Rasoul Mohammadi; dr.rasoul_mohammadi@yahoo.com
}

Received 13 May 2021; Revised 25 August 2021; Accepted 8 September 2021; Published 16 September 2021

Academic Editor: Rizgar Mageed

Copyright (c) 2021 Mostafa Chadeganipour et al. This is an open access article distributed under the Creative Commons Attribution License, which permits unrestricted use, distribution, and reproduction in any medium, provided the original work is properly cited.

\begin{abstract}
Background. Psoriasis is a chronic inflammatory disorder of the skin and joint, affecting nearly 2-3\% of the general population. It is assumed that imbalance between the types of natural microflora can accelerate the onset of the disease. Some fungi can play the role of superantigens and prolong chronic inflammation in the skin of psoriatic patients. The aim of the present investigation was to identify fungal species isolated from patients with psoriasis. Methods. From March 2016 to May 2019, 289 patients with prior diagnosis of psoriasis were included in this survey. Direct microscopy with potassium hydroxide (KOH $10 \%)$, culture, urea hydrolysis, hair perforation test, and growth on rice grains were used to identify clinical isolates, phenotypically. For molecular identification of Candida species and Malassezia species, PCR-RFLP and PCR-sequencing were used, respectively. Results. Fortysix out of 289 psoriatic patients had fungal infections (15.9\%). Dermatophytes (54.3\%), Candida spp. (19.5\%), Malassezia spp. (15.2\%), Aspergillus spp. (6.5\%), and Fusarium spp. (4.3\%) were the causative agents of fungal infections. Among Malassezia and Candida species, $M$. restricta (10.8\%) and C. glabrata (8.7\%) were the most prevalent species, respectively. Conclusion. Our findings suggested that fungal pathogens, particularly dermatophytes, may play an important role in the pathogenicity of psoriasis. Also, due to the high rate of yeast colonization in the clinical samples of psoriatic patients, concomitant use of anti-inflammatory drugs and antifungals may represent an effective therapeutic approach for better management of chronic lesions among these patients. Mycological tests should be applied to indicate the incidence of fungal diseases in psoriatic patients.
\end{abstract}

\section{Introduction}

Psoriasis is an immune-mediated inflammatory disorder affecting $2-3 \%$ of the general population [1]. Dysregulation of the immune system such as keratinocyte hyperproliferation and infiltration of inflammatory cells, especially monocytes, neutrophils, dendritic cells, and T lymphocytes in the epidermis and dermis, is now considered as a decisive phenomenon in the pathogenesis of psoriasis [2]. Although the nature of the microbial antigen or autoantigen that triggers psoriatic $\mathrm{T}$ cells remains contentious, interactions among Th1, Th17, Th9, Th22, and Treg cells seem to be important factors for the progression of psoriasis [3]. Also, endotoxins of Gram-negative bacteria, endogenous bacteria, dermatophyte infections, and intestinal yeasts may be involved in the development of psoriasis
[4-6]. Psoriasis is a multiorgan dysfunction that commonly occurs in patients with obesity, systemic arterial hypertension, type 2 diabetes, cardiovascular diseases, anxiety, and nonalcoholic fatty liver disease $[7,8]$. The objective of the present investigation was to assess fungal infections among psoriatic patients and the identification of etiologic agents by phenotypic and molecular techniques.

\section{Materials and Methods}

This is a cross-sectional study conducted at a mycology reference laboratory (Shefa Lab.) in Isfahan, Iran. Between March 2016 and May 2019, 289 patients with prior diagnosis of psoriasis who revealed nail or skin changes were included in this survey. Psoriasis was diagnosed and confirmed by dermatologists at the specialized clinics. Patients taking 
topical or systemic antifungal agents in the previous 15 days were excluded from the study $(n=17)$. Age, sex, job, location on the body, and clinical manifestations were documented for each patient. This research was approved by the Ethics Committee of Isfahan University of Medical Science (no. IR.MUI.MED.REC.1398.634), and written informed consent was obtained from all patients.

2.1. Conventional Methods. Nail clippings and skin scrapings were collected in sterile Petri dishes for direct microscopic examination (DME) and culture. Potassium hydroxide $(\mathrm{KOH}) \quad 10 \%$ and $20 \%+$ dimethyl sulfoxide (DMSO) were used for DME of skin scrapings and nail clippings, respectively. Sabouraud dextrose agar with chloramphenicol and cycloheximide (Mycobiotic agar; Difco, Detroit, MI) (for dermatophyte spp.), Czapek-Dox agar (QUELAB, Quebec, Canada) (for Aspergillus spp.), Sabouraud glucose agar (Difco, Detroit, MI), and Dixon's agar (HiMedia, India) (for Malassezia spp.) were applied for culture and incubated at $30^{\circ} \mathrm{C}$ and $37^{\circ} \mathrm{C}$. Cultures were examined continuously for the fungal growth up to 4 weeks. Additional diagnostic tests such as urea hydrolysis (QUELAB, Canada), culture on nutritional media (Trichophyton agars; BIOMARK, India), hair perforation test, and growth on rice grains were used to confirm primary identification of dermatophyte spp. $[9,10]$.

\subsection{Molecular Identification of Candida Species}

2.2.1. DNA Extraction. Genomic DNA was extracted using the boiling method [11]. In brief, a loopful of fresh colonies was suspended in $80 \mu \mathrm{L}$ of double distilled water and boiled for 10 minutes and then centrifuged for 6 minutes at $6500 \mathrm{rpm}$. The supernatant containing DNA was used for PCR.

\subsubsection{Polymerase Chain Reaction-Restriction Fragment} Length Polymorphism (PCR-RFLP). ITS1-5.8SrDNA-ITS2 region was amplified by a PCR mixture containing $5 \mu \mathrm{L}$ of $10 \times$ reaction buffer, $1.5 \mathrm{mM} \mathrm{MgCl}_{2}, 0.4 \mathrm{mM}$ dNTPs, $30 \mathrm{pmol}$ ITS1 ( $5^{\prime}$-TCC GTA GGT GAA CCT GCG G-3') and 30 pmol ITS4 (5'-TCC TCC GCT TAT TGA TAT GC-3') primers [12], $2.5 \mathrm{U}$ of Taq polymerase, and $3 \mu \mathrm{L}$ DNA in a final volume of $50 \mu \mathrm{L}$. The PCR cycling conditions were as follows: an initial denaturation phase at $95^{\circ} \mathrm{C}$ for $5 \mathrm{~min}$, followed by 30 cycles of denaturation at $95^{\circ} \mathrm{C}$ for $30 \mathrm{~s}$, annealing at $55^{\circ} \mathrm{C}$ for $45 \mathrm{~s}$, and extension at $72^{\circ} \mathrm{C}$ for $1 \mathrm{~min}$, with a final extension phase at $72^{\circ} \mathrm{C}$ for $7 \mathrm{~min}$. PCR products were digested with the HpaII (MspI) restriction enzyme (Fermentas, Vilnius, Lithuania). Five microliter of each PCR products and $10 \mu \mathrm{L}$ of RFLP amplicons were separated by gel electrophoresis on $1.5 \%$ and $2 \%$ agarose gel (containing $0.5 \mu \mathrm{g} / \mathrm{mL}$ ethidium bromide), respectively.

\subsection{Molecular Identification of Malassezia Species}

2.3.1. DNA Extraction. Genomic DNA was extracted from the skin scrapings and dandruff or from colonies subcultured on Dixon's agar (HiMedia, India) by using glass beads and phenol/chloroform techniques $[13,14]$. In brief, a loopful of the skin scale or dandruff was transferred to a $1.5 \mathrm{~mL}$ Eppendorf tube, including $300 \mu \mathrm{L}$ glass beads and $300 \mu \mathrm{L}$ lysis buffer $(200 \mathrm{mM}$ Tris/ $\mathrm{HCl}$ with a $\mathrm{pH}$ of 7.5 , $25 \mathrm{mM}$ EDTA, 0.5\% SDS, and $250 \mathrm{mM} \mathrm{NaCl}$ ). Afterwards, the specimens were centrifuged for $1 \mathrm{~min}$ at 7,000 rpm and then $300 \mu \mathrm{L}$ of phenol/chloroform was added, followed by vortexing and centrifugation for $6 \mathrm{~min}$ at 5,000 rpm. In the following, the supernatant was transferred to a new tube, and the same amount of chloroform was added to it and centrifuged for $7 \mathrm{~min}$ at $6,000 \mathrm{rpm}$. Subsequently, the supernatant was transferred to a new tube, and then alcohol (2.5 times) and $3 \mathrm{M}$ sodium acetate (1/10 volume) were added and stored at $-20{ }^{\circ} \mathrm{C}$ for $1 \mathrm{~h}$ and centrifuged for $5 \mathrm{~min}$ at 10,000 . The supernatant was removed, and $500 \mu \mathrm{L}$ alcohol $70 \%$ was added to the pellet, which was then centrifuged for $12 \mathrm{~min}$ at 12,000 rpm. At the final stage, the supernatant was discarded, and $50 \mu \mathrm{L}$ double distilled water was added and kept at $-20{ }^{\circ} \mathrm{C}$.

2.3.2. Amplification of D1/D2 Region of $26 S$ rDNA. PCR reaction included $5 \mu \mathrm{L}$ of $10 \times \mathrm{PCR}$ buffer, $1.5 \mathrm{mM} \mathrm{MgCl}_{2}$, $0.5 \mathrm{mM}$ of each forward (5' $5^{\prime}$ TAACAAGGATTCCCCTAGTA$\left.3^{\prime}\right)$ and reverse ( $5^{\prime}$-ATTACGCCAGCATCCTAAG- $\left.3^{\prime}\right)$ primers [15], $0.2 \mathrm{mM}$ of each deoxynucleoside triphosphate, $1.25 \mathrm{U}$ of Taq polymerase, and $2 \mu \mathrm{l}$ template DNA in a final volume of $50 \mu \mathrm{l}$. The PCR conditions were as follows: an initial denaturation step at $94^{\circ} \mathrm{C}$ for $5 \mathrm{~min}$, followed by 34 cycles of denaturation at $94^{\circ} \mathrm{C}$ for $45 \mathrm{sec}$, annealing at $55^{\circ} \mathrm{C}$ for $45 \mathrm{sec}$, and extension at $72^{\circ} \mathrm{C}$ for $1 \mathrm{~min}$, with a final extension step of $72^{\circ} \mathrm{C}$ for $7 \mathrm{~min}$. The PCR products were visualized by $1.5 \%(\mathrm{w} / \mathrm{v})$ agarose gel electrophoresis in TBE buffer, stained with SYBR Safe DNA gel stain $(1: 10,000$ dilution in TBE), and photographed under ultraviolet transilluminator (UVITEC, UK).

2.3.3. Sequencing. All amplicons were subjected to sequence analysis. They were purified by the ethanol purification method, and cycle sequencing reactions were performed in a forward direction (Bioneer, South Korea). The sequencing products were evaluated with Chromas 2.4 (https://chromas. software.informer.com/2.4/) and analyzed using the NCBI BLAST searches against fungal sequences existing in DNA databases (https://blast.ncbi.nlm.nih.gov/Blast.cgi).

2.4. Statistical Analysis. Chi-square and Fisher's exact tests in the SPSS software version 23 (IBM Corp, Armonk, NY) were applied for analysis. A $p$ value less than 0.05 was considered statistically significant. 


\section{Results}

Forty-six out of 289 psoriatic patients had fungal infections (15.9\%). The male to female ratio of participants was 28/18. The age range of the patients was between 10 and 82 years. The age ranges of $11-20(23.9 \%)$ and $81-90(2.2 \%)$ years had the highest and lowest frequencies, respectively (Table 1). Students were the most commonly infected population (26.1\%) followed by employees (23.9\%) and housewives (21.7\%) (Figure 1). Diabetes mellitus (19.6\%), atopic dermatitis (13\%), use of corticosteroid (10.9\%), and use of wide spectrum antibiotics $(8.7 \%)$ were the most predisposing factors for fungal infections. Obesity, cardiovascular diseases, and smoking were main comorbid diseases among psoriatic patients (Table 2). Dermatophytes (54.3\%), Candida spp. (19.5\%), Malassezia spp. (15.2\%), Aspergillus spp. (6.5\%), and Fusarium spp. (4.3\%) were the causative agents of fungal infections in the present study (Table 3). Among Malassezia and Candida species, M. restricta (10.8\%) and C. glabrata (8.7\%) were the most prevalent species, respectively. Interestingly, none of the Candida species were albicans (Figure 2). All sequences of Malassezia spp. were deposited the in the GenBank under the accession numbers MT645556, MT645557, MT645569, MT645570, MT645572, MT645573, and MT645587. Fisher's exact test showed that the association between the psoriasis and fungal species was not statistically significant $(p=0.88)$.

\section{Discussion}

Over the past decade, the connection between the inflammatory skin disorders and microbiome has been increasingly accepted [16]. It is assumed that imbalance between the types of natural microflora of the skin and mucosa could accelerate the onset of the disease in vulnerable hosts such as patients with autoimmune disorders [17]. Various microorganisms including fungi, viruses, and bacteria can play the role of superantigens (SAgs) that trigger specific T cells and initiate, intensify, and prolong chronic inflammation in skin disorders [18]. For example, it has been proven for Staphylococcus aureus skin colonization in psoriasis and atopic dermatitis $[19,20]$. Similar to bacteria, many fungi have also been recognized in encouraging skin-associated lymphoid tissue. Candida species are important part of the human microflora, commonly colonizing the mucosal membranes of genitourinary and gastroesophageal tracts and skin. They cause infection in patients with impaired immune system [21]. Despite the fact that the significant role of the microorganisms in the pathogenesis of inflammatory skin disorders has been remarkably analyzed, this connection has been overlooked in the case of fungi. Excessive growth of Candida species has been found on the skin of patients with inflammatory skin disorders such as psoriasis and atopic dermatitis [22]. Candida strain antigens, mainly surface proteins of $C$. albicans, have been proven to have superantigen-like sequel, following the polyclonal T cell activation and uncontrolled release of proinflammatory cytokines [23]. In a meta-analysis performed by Pietrzak et al. [21], all analyzed investigations revealed a higher oral colonization
TABLE 1: The distribution of psoriatic patients with fungal infections in different age categories.

\begin{tabular}{lccc}
\hline Age group & Male & Female & Total \\
\hline $0-10$ & 1 & 1 & 2 \\
$11-20$ & 7 & 4 & 11 \\
$21-30$ & 4 & 4 & 8 \\
$31-40$ & 5 & 1 & 6 \\
$41-50$ & 3 & 4 & 7 \\
$51-60$ & 4 & 1 & 5 \\
$61-70$ & 1 & 2 & 3 \\
$71-80$ & 2 & 1 & 3 \\
$81-90$ & 1 & 0 & 1 \\
Total & 28 & 18 & 46 \\
\hline
\end{tabular}

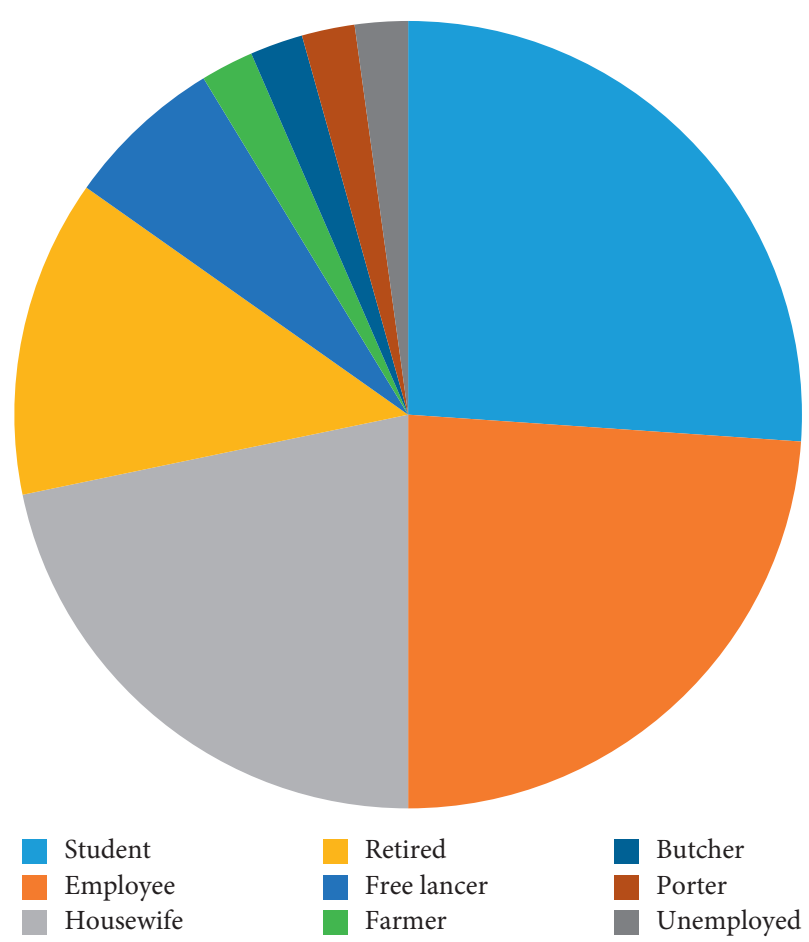

FIGURE 1: Distribution of psoriatic patients with fungal infections according to their occupation: student $(n=12)$, employee $(n=11)$, housewife $(n=10)$, retired $(n=6)$, freelancer $(n=3)$, farmer $(n=1)$, butcher $(n=1)$, porter $(n=1)$, and unemployed $(n=1)$.

TABle 2: Comorbid diseases in psoriatic patients in the present study.

\begin{tabular}{lc}
\hline Comorbid diseases & Number \\
\hline Obesity & $14(30.4 \%)$ \\
Cardiovascular diseases & $9(19.5 \%)$ \\
Smoking & $7(15.2 \%)$ \\
Nonalcoholic fatty liver disease & $5(10.8 \%)$ \\
Celiac disease & $2(4.3 \%)$ \\
Lymphoma & $2(4.3 \%)$ \\
Anxiety & $2(4.3 \%)$ \\
Parkinson's disease & $1(2.2 \%)$ \\
Unknown & $4(8.7 \%)$ \\
\hline
\end{tabular}


TABLE 3: Etiologic agents of fungal infections isolated from psoriatic patients.

\begin{tabular}{|c|c|c|c|c|c|c|c|c|c|c|}
\hline \multirow[b]{2}{*}{ Etiologic agent } & \multirow[b]{2}{*}{ Methods of identification } & \multicolumn{9}{|c|}{ Infected area } \\
\hline & & Hand & Face & Scalp & Nail & Foot & $\begin{array}{c}\text { Glabrous } \\
\text { skin }\end{array}$ & Groin & Eyebrow & Total \\
\hline T. rubrum & $\mathrm{DM}+$ culture + additional tests $^{\mathrm{a}}$ & 1 & 0 & 0 & $\begin{array}{l}1(\mathrm{FN}) \\
2(\mathrm{TN})\end{array}$ & 1 & 0 & 0 & 0 & 5 \\
\hline E. floccosum & $\mathrm{DM}+$ culture + additional tests & 0 & 0 & 0 & $3(\mathrm{TN})$ & 3 & 0 & 1 & 0 & 7 \\
\hline $\begin{array}{l}\text { T. interdigitale/ } \\
\text { mentagrophytes }\end{array}$ & $\mathrm{DM}+$ culture + additional tests & 0 & 0 & 0 & $\begin{array}{l}1(\mathrm{FN}) \\
5(\mathrm{TN})\end{array}$ & 2 & 1 & 0 & 0 & 9 \\
\hline T. verrucosum & $\mathrm{DM}+$ culture + additional tests & 0 & 1 & 0 & 0 & 0 & 0 & 0 & 0 & 1 \\
\hline T. violaceum & $\mathrm{DM}+$ culture + additional tests & 0 & 0 & 1 & 0 & 0 & 0 & 0 & 0 & 1 \\
\hline M. gypseum & $\mathrm{DM}+$ culture + additional tests & 0 & 0 & 1 & 0 & 0 & 0 & 0 & 0 & 1 \\
\hline M. canis & $\mathrm{DM}+$ culture + additional tests & 0 & 1 & 0 & 0 & 0 & 0 & 0 & 0 & 1 \\
\hline C. glabrata & PCR-RFLP & 0 & 0 & 0 & $\begin{array}{l}2(\mathrm{FN}) \\
1(\mathrm{TN})\end{array}$ & 0 & 1 & 0 & 0 & 4 \\
\hline C. krusei & PCR-RFLP & 0 & 0 & 0 & $1(\mathrm{FN})$ & 0 & 1 & 0 & 0 & 2 \\
\hline C. parapsilosis & PCR-RFLP & 0 & 0 & 0 & $3(\mathrm{FN})$ & 0 & 0 & 0 & 0 & 3 \\
\hline M. restricta & PCR-sequencing & 0 & 1 & 2 & 0 & 0 & 0 & 0 & 2 & 5 \\
\hline M. globosa & PCR-sequencing & 0 & 0 & 1 & 0 & 0 & 0 & 0 & 1 & 2 \\
\hline Aspergillus sp. & $\mathrm{DM}+$ culture & 0 & 0 & 0 & $\begin{array}{l}1(\mathrm{FN}) \\
2(\mathrm{TN})\end{array}$ & 0 & 0 & 0 & 0 & 3 \\
\hline Fusarium sp. & $\mathrm{DM}+$ culture & 0 & 0 & 0 & $\begin{array}{l}1(\mathrm{FN}) \\
1(\mathrm{TN})\end{array}$ & 0 & 0 & 0 & 0 & 2 \\
\hline Total & & 1 & 3 & 5 & 24 & 6 & 3 & 1 & 3 & 46 \\
\hline
\end{tabular}

FN: finger nail, TN: toe nail, DM: direct microscopy, and PCR-RFLP: polymerase chain reaction-restriction fragment length polymorphism. ${ }^{\mathrm{a}} \mathrm{Additional}$ tests including urea hydrolysis, hair perforation test, and growth on rice grains were used to confirm primary identification of dermatophyte species.

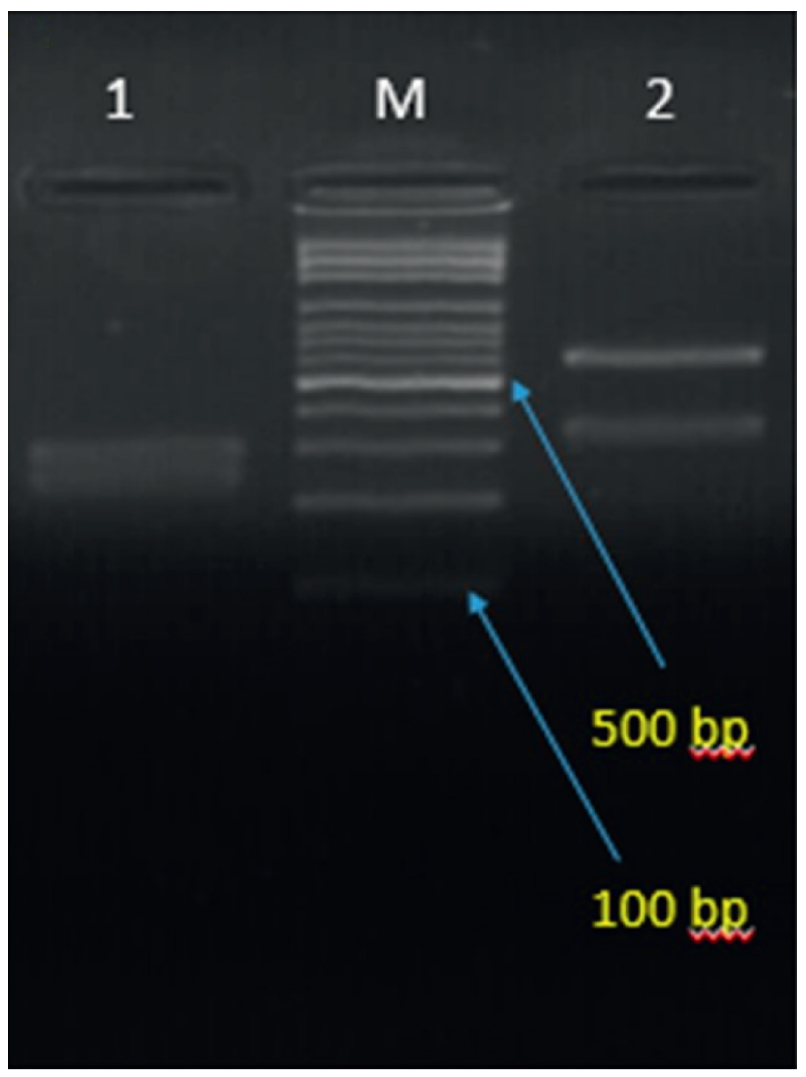

(a)

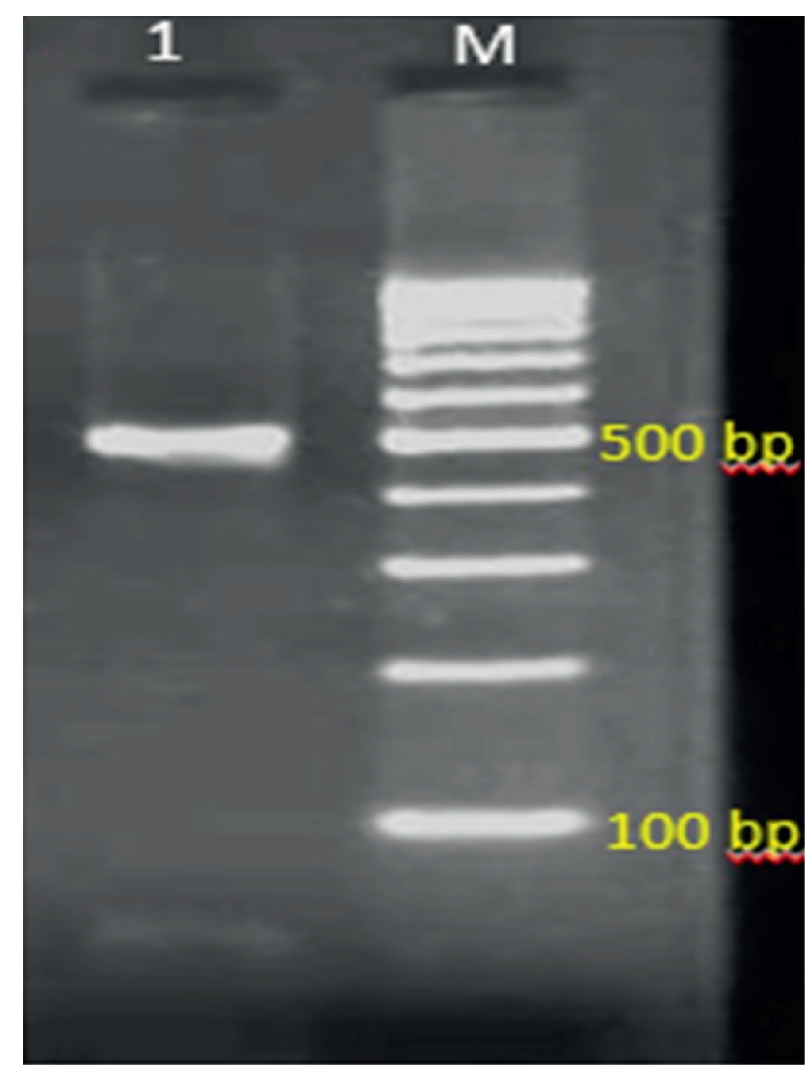

(b)

Figure 2: Digested ITS-PCR products with MspI. (a) Lane 1: C. krusei; lane M: 100 bp DNA size marker; and lane 2: C. glabrata. (b) Lane 1: C. parapsilosis and lane M: 100 bp DNA size marker. 
by Candida among psoriatic patients. They suggested that psoriasis may be one of the systemic disorders that induces oral candidiasis; nevertheless, we did not detect oral colonization or oropharyngeal candidiasis in psoriatic patients in the present study. Picciani et al. showed that $26 \%$ of psoriatic patients had oral candidiasis in comparison with the control group [24]. Antimicrobial peptides (AMPs), which are exceedingly produced in the skin of psoriatic patients, can inhibit Candida spp. growth [25]; however, Taheri Sarvtin et al. reported that Candida species were isolated from skin samples of $15 \%$ of psoriatic patients compared to $4 \%$ of healthy individuals [26]. We isolated Candida spp. from skin scrapings of $4.3 \%$ of patients with psoriasis. Candida species, mainly C. albicans, are the most prevalent pathogens isolated in clinical samples of patients with psoriasis vulgaris [4], but none of Candida species were albicans in the present survey (Figure 2). Although males and females are identically affected by psoriasis vulgaris, within the younger patients, females are more likely to be affected than males [2]. Antifungal drugs have been shown to reduce inflammation in psoriasis [4]; however, we did not evaluate the effects of this variable because the use of antifungal drugs was one of the exclusion criteria in our study. The occurrence of onychomycosis in psoriatic patients is controversial, ranging from $10 \%$ to $56 \%[5,27]$. A possible explanation is that the pathological changes of nails in psoriasis, such as hyperkeratosis, pitting, and onycholysis, are intricate to discern clinically from onychomycosis, and precise assessment relies on mycological tests. High prevalence of onychomycosis among psoriatic patients may related to abnormal capillary unit in psoriatic nails that damages the immune defenses generally supplied by the intact hyponychium and the use of immunosuppressive agents among psoriatic patients. On the other hand, faster turnover of nails in psoriatic patients may be noticed as a significant defense mechanism against fungal invasion [28]. One of the limitations of the present investigation was the lack of control group to compare the rate of onychomycosis in psoriatic patients and control population; nevertheless, the majority of fungal infections in our study belonged to the nail infections (52.2\%). This is less than the nail involvement reported by Jendoubi et al. [28] and Zargari et al. [29] which were $71.2 \%$ and $69.5 \%$, respectively. In line with our findings, nail pitting is the most common nail matrix involvement among psoriatic patients [30]. Some literatures revealed that $85-90 \%$ of patients with psoriasis expand nail involvement in their lifetime [31], but $73 \%$ of patients had nail psoriasis in the present study. Leibovici et al. [27] showed a higher prevalence of nail infection in males and elderly patients. In agreement, we also found a higher frequency of onychomycosis in males; however, teens were the most infected population in our survey. Some studies confirm our findings [32, 33], and others deny it $[34,35]$. Leibovici et al. reported a higher percentage of dermatophytes as the etiologic agents of fungal infection with the most distribution of Trichophyton rubrum (35.4\%) among clinical specimens [27], whereas Epidermophyton floccosum and T. interdigitale/mentagrophytes were the most common dermatophyte species in the present investigation $(30 \%)$. Although, in some papers, the prevalence of dermatophytosis is lower in psoriatic patients $[36,37]$, in other studies, the prevalence of this infection is higher among psoriatic patients compared to the control group $[5,38]$.

\section{Conclusion}

The prevalence of fungal infections among psoriatic patients is controversial. Our findings suggested that fungal pathogens, particularly dermatophytes, may play an important role in the pathogenicity of psoriasis. Also, due to the high rate of yeast colonization in clinical samples of psoriatic patients, concomitant use of anti-inflammatory drugs and antifungals may represent an effective therapeutic approach for better management of chronic lesions among these patients. Furthermore, we found that the occurrence of fungal infections in psoriatic patients is not as uncommon as generally believed. Mycological tests should be applied to indicate the incidence of fungal diseases in psoriatic patients.

\section{Data Availability}

The data on which this research is based are available from the corresponding author upon request. In addition, the sequence data used to support the findings of this study have been deposited in the GenBank repository (https://www. ncbi.nlm.nih.gov/genbank/sequenceids/) under the accession numbers MT645556, MT645557, MT645569, MT645570, MT645572, MT645573, and MT645587.

\section{Conflicts of Interest}

The authors declare that there are no conflicts of interest regarding the publication of this paper.

\section{Acknowledgments}

The authors appreciate Shefa Laboratory personnel for data collection of patients. This study was supported by Isfahan University of Medical Sciences, Isfahan, Iran (no. 298224).

\section{References}

[1] C. E. M. Griffiths, E. Christophers, J. N. W. N. Barker et al., "A classification of psoriasis vulgaris according to phenotype," British Journal of Dermatology, vol. 156, no. 2, pp. 258-262, 2007.

[2] S. Sepahi, B. Riahi-Zanjani, and A. Ghorani-Azam, "The role of Candida albicans in the pathogenesis of psoriasis vulgaris: a systematic literature review," Reviews in Clinical Medicine, vol. 3, pp. 122-127, 2016.

[3] Y. Cai, C. Fleming, and J. Yan, "New insights of T cells in the pathogenesis of psoriasis," Cellular and Molecular Immunology, vol. 9, no. 4, pp. 302-309, 2012.

[4] A. Waldman, A. Gilhar, L. Duek, and I. Berdicevsky, "Incidence of Candida in psoriasis-a study on the fungal flora of psoriatic patients," Mycoses, vol. 44, no. 3-4, pp. 77-81, 2001.

[5] A. K. Gupta, C. W. Lynde, H. C. Jain et al., "A higher prevalence of onychomycosis in psoriatics compared with non-psoriatics: a multicentre study," British Journal of Dermatology, vol. 136, no. 5, pp. 786-789, 1997. 
[6] N. Hamnerius, J. Berglund, and J. Faergemann, "Pedal dermatophyte infection in psoriasis," British Journal of Dermatology, vol. 150, no. 6, pp. 1125-1128, 2004.

[7] A. Ventura, M. Mazzeo, R. Gaziano, M. Galluzzo, L. Bianchi, and E. Campione, "New insight into the pathogenesis of nail psoriasis and overview of treatment strategies," Drug Design, Development and Therapy, vol. 11, pp. 2527-2535, 2017.

[8] K. R. R. Schons, C. F. Knob, N. Murussi, A. A. C. Beber, W. Neumaier, and O. A. Monticielo, "Nail psoriasis: a review of the literature," Anais Brasileiros de Dermatologia, vol. 89, no. 2, pp. 312-317, 2014.

[9] I. Weitzman and R. C. Summerbell, "The dermatophytes," Clinical Microbiology Reviews, vol. 8, no. 2, pp. 240-259, 1995.

[10] R. Robert and M. Pihet, "Conventional methods for the diagnosis of dermatophytosis," Mycopathologia, vol. 166, no. 56, pp. 295-306, 2008.

[11] G. A. d. Silva, T. L. Bernardi, P. D. C. Schaker, M. Menegotto, and P. Valente, "Rapid yeast DNA extraction by boiling and freeze-thawing without using chemical reagents and DNA purification," Brazilian Archives of Biology and Technology, vol. 55, no. 2, pp. 319-327, 2012.

[12] T. J. White, T. Bruns, S. Lee, and J. Taylor, "Amplification and direct sequencing of fungal ribosomal RNA genes for phylogenetics," in PCR Protocols: A Guide to Methods and Applications, M. A. Innis, D. H. Gelfand, J. J. Sninsky, and T. J. White, Eds., Academic Press, London, UK, pp. 315-322, 1990.

[13] Y. Yamada, K. Makimura, H. Merhendi et al., "Comparison of different methods for extraction of mitochondrial DNA from human pathogenic yeasts," Japanese Journal of Infectious Diseases, vol. 55, pp. 122-125, 2002.

[14] M. Gholami, F. Mokhtari, and R. Mohammadi, "Identification of Malassezia species using direct PCR-sequencing on clinical samples from patients with pityriasis versicolor and seborrheic dermatitis," Current Medical Mycology, vol. 6, pp. 21-26, 2020.

[15] H. Mirhendi, K. Makimura, K. Zomorodian, T. Yamada, T. Sugita, and H. Yamaguchi, "A simple PCR-RFLP method for identification and differentiation of 11 Malassezia species," Journal of Microbiological Methods, vol. 61, no. 2, pp. 281-284, 2005.

[16] B. Dréno, E. Araviiskaia, E. Berardesca et al., "Microbiome in healthy skin, update for dermatologists," Journal of the European Academy of Dermatology and Venereology, vol. 30, no. 12, pp. 2038-2047, 2016.

[17] M. Maguire and G. Maguire, "The role of microbiota, and probiotics and prebiotics in skin health," Archives of Dermatological Research, vol. 309, no. 6, pp. 411-421, 2017.

[18] E. S. Macias, F. A. Pereira, W. Rietkerk, and B. Safai, "Superantigens in dermatology," Journal of the American Academy of Dermatology, vol. 64, no. 3, pp. 455-472, 2011.

[19] J. E. E. Totté, W. T. Van Der Feltz, M. Hennekam, A. van Belkum, E. J. Van Zuuren, and S. G. M. A. Pasmans, "Prevalence and odds of Staphylococcus aureus carriage in atopic dermatitis: a systematic review and meta-analysis," British Journal of Dermatology, vol. 175, no. 4, pp. 687-695, 2016.

[20] J. E. E. Totté, W. T. Van der Feltz, L. G. M. Bode, A. van Belkum, E. J. Van Zuuren, and S. G. M. A. Pasmans, "A systematic review and meta-analysis on Staphylococcus aureus carriage in psoriasis, acne and rosacea," European Journal of Clinical Microbiology \& Infectious Diseases, vol. 35, no. 7, pp. 1069-1077, 2016.
[21] A. Pietrzak, E. Grywalska, M. Socha et al., "Prevalence and possible role of Candida species in patients with psoriasis: a systematic review and meta-analysis," Mediators of Inflammation, vol. 2018, Article ID 9602362, 7 pages, 2018.

[22] G. Javad, M. Taheri Sarvtin, M. T. Hedayati, Z. Hajheydari, J. Yazdani, and T. Shokohi, "Evaluation of Candida colonization and specific humoral responses against Candida albicans in patients with atopic dermatitis," BioMed Research International, vol. 2015, Article ID 849206, 5 pages, 2015.

[23] D. Devore-Carter, S. Kar, V. Vellucci, V. Bhattacherjee, P. Domanski, and M. K. Hostetter, "Superantigen-like effects of a Candida albicans polypeptide," International Journal of Infectious Diseases, vol. 197, pp. 981-989, 2008.

[24] B. L. S. Picciani, B. Michalski-Santos, S. Carneiro et al., "Oral candidiasis in patients with psoriasis: correlation of oral examination and cytopathological evaluation with psoriasis disease severity and treatment," Journal of the American Academy of Dermatology, vol. 68, no. 6, pp. 986-991, 2013.

[25] M. Marcinkiewicz and S. Majewski, "The role of antimicrobial peptides in chronic inflammatory skin diseases," Advances in Dermatology and Allergology, vol. 1, pp. 6-12, 2016.

[26] M. Taheri Sarvtin, T. Shokohi, Z. Hajheydari, J. Yazdani, and M. T. Hedayati, "Evaluation of Candidal colonization and specific humoral responses against Candida albicansin patients with psoriasis," International Journal of Dermatology, vol. 53, no. 12, pp. e555-e560, 2014.

[27] V. Leibovici, K. Hershko, A. Ingber, M. Westerman, N. Leviatan-Strauss, and M. Hochberg, "Increased prevalence of onychomycosis among psoriatic patients in Israel," Acta Dermato-Venereologica, vol. 88, no. 1, pp. 31-33, 2008.

[28] F. Jendoubi, I. Ben Lagha, F. Rabhi et al., "Nail involvement in psoriatic patients and association with onychomycosis: results from a cross-sectional study performed in a military hospital in Tunisia," Skin Appendage Disorders, vol. 5, no. 5, pp. 299-303, 2019.

[29] O. Zargari, E. K. Leyli, and S. Z. Azimi, "Nail involvement in patients with psoriatic arthritis in Northern Iran," Autoimmune Diseases, vol. 2018, 6 pages, 2018.

[30] H. M. J. van der Velden, K. M. G. Klaassen, P. C. M. van de Kerkhof, and M. C. Pasch, "Fingernail psoriasis reconsidered: a case-control study," Journal of the American Academy of Dermatology, vol. 69, no. 2, pp. 245252, 2013.

[31] R. G. Langley and E. Daudén, "Treatment and management of psoriasis with nail involvement: a focus on biologic therapy," Dermatology, vol. 221, no. 1, pp. 29-42, 2010.

[32] J. Salomon, J. C. Szepietowski, and A. Proniewicz, "Psoriatic nails: a prospective clinical study," Journal of Cutaneous Medicine and Surgery, vol. 7, no. 4, pp. 317-321, 2003.

[33] S. N. Tham, J. J. Lim, S. H. Tay et al., "Clinical observations on nail changes in psoriasis," Annals Academy of Medicine Singapore, vol. 17, pp. 482-485, 1988.

[34] V. Brazzelli, A. Carugno, A. Alborghetti et al., "Prevalence, severity and clinical features of psoriasis in fingernails and toenails in adult patients: Italian experience," Journal of the European Academy of Dermatology and Venereology, vol. 26, no. 11, pp. 1354-1359, 2012.

[35] Z. Hallaji, F. Babaeijandaghi, M. Akbarzadeh et al., "A significant association exists between the severity of nail and skin involvement in psoriasis," Journal of the American Academy of Dermatology, vol. 66, no. 1, pp. e12-e13, 2012.

[36] E. Kocsard, "Associated dermatoses and triggering factors in psoriasis," Australasian Journal of Dermatology, vol. 15, no. 2, pp. 64-76, 1974. 
[37] J. Fransson, K. Storgårds, and H. Hammar, "Palmoplantar lesions in psoriatic patients and their relation to inverse psoriasis, tinea infection and contact allergy," Acta DermatoVenereologica, vol. 65, pp. 218-223, 1985.

[38] B. Staberg, M. Gammeltoft, and P. Onsberg, "Onychomycosis in patients with psoriasis," Acta Dermato-Venereologica, vol. 63, pp. 436-438, 1983. 